\title{
Application of Trochanteric Flip Osteotomy with Herbert Screw to Treat Pipkin I,II Fracture of the Femoral Head
}

\author{
Kai Sun ${ }^{1}$, Lin Zhou ${ }^{2}$, Zhizhong $\mathrm{Li}^{2,}$ * \\ ${ }^{1}$ the First Clinical Medical College; Jinan University, Guang Zhou, China \\ ${ }^{2}$ Department of Osteology, the First Affiliated Hospital of Jinan University, Guang Zhou, China \\ Email address: \\ 349613262@qq.com (Kai Sun), linzhou8581@hotmail.com (Lin Zhou),793112797@qq.com (Zhizhong L) \\ ${ }^{*}$ Corresponding author
}

\section{To cite this article:}

Kai Sun, Lin Zhou, Zhizhong Li. Application of Trochanteric Flip Osteotomy with Herbert Screw to Treat Pipkin I,II Fracture of the Femoral Head. Journal of Surgery. Vol. 4, No. 5, 2016, pp. 100-104. doi: 10.11648/j.js.20160405.13

Received: August 8, 2016; Accepted: August 16, 2016; Published: September 2, 2016

\begin{abstract}
There is no definite protocol in management of Pipkin fracture in relation to operation approach and internal fixations. The aim is to explore the therapeutic effects of internal fixation with Herbert screws for the treatment of Pipkin type I and type II femoral head fractures through the trochanteric flip osteotomy (TFO) approach. From January 2010 to December 2014, 12 cases of type I and II Pipkin fracture (including 8 type I,4 type II) treated through TFO approach and internal fixation with Herbert screws. All the patients were followed up 1-4 years with an average of 2.6 years. The whole osteotomies and acetabular fractures healed within 6 to 12 weeks. All patients achieved healing of femoral head fracture after 12-16 months without femoral head necrosis. Heterotopic ossification (HO) occurred in 1 cases after operation which were left untreated. At the last follow-up, excellent and good rate was 91.7\%. Treatment of type I, II Pipkin fracture through TFO approach can provide good visualization and protect of the femoral head blood supply. The treatment of internal fixation with Herbert screws is effective for Pipkin type I and type II femoral head fracture.
\end{abstract}

Keywords: Pipkin Fracture, Trochanteric Flip Osteotomy, Herbert Screw, Internal Fixation

\section{Introduction}

Dr. John Birkett first described the fracture of femoral head in 1869 in a 35-year-old woman [1]. Femoral head fractures are rare injuries and they represent a severe injury to the hip joint and historically have been associated with a relatively poor functional outcome. The most widely used classification was that of Pipkin which is based on the location of the femoral head fracture in relation to the fovea and additional lesion on the femoral neck or acetabulum. Pipkin Type I is femoral head fracture inferior to the fovea centralis. Type II fracture extended superior to the fovea centralis. Type III any femoral head fracture with an associated femoral neck fracture. Type IV any femoral head fracture with an associated acetabular fracture [2]. About 55-65\% of femoral head fractures have been reported to be Type I and Type II. There is still no consensus on the management of Pipkin type I and type II injuries: whether to treat these fractures operatively or non-operatively, whether to fix or excise the head fragment, or which surgical approach to use.

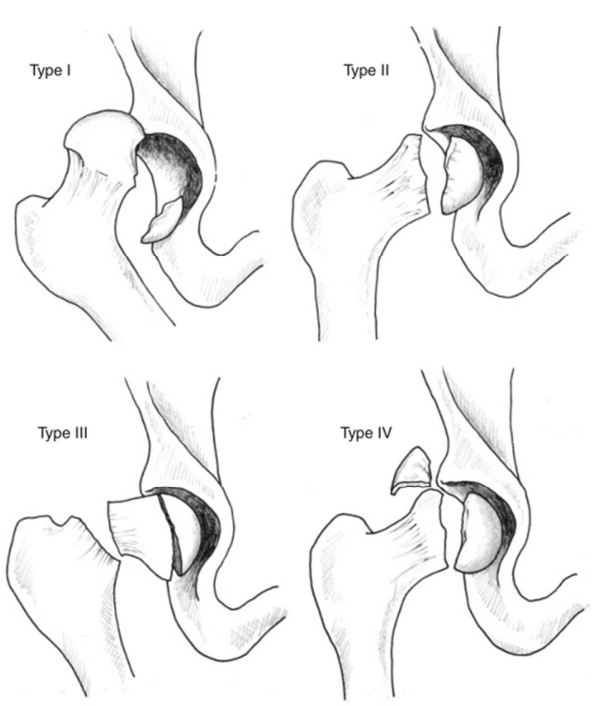

Fig. 1. The Pipkin classification of femoral head fractures [2]. 
Surgery for Pipkin I and II fractures generally has focused on through the TFO, which has been widely suggested for management of femoral head fractures. This technique allows larger exposure and repair fractures without compromising the femoral head vasculature. We report the radiographic outcomes, including rates of femoral head osteonecrosis and heterotopic ossification (HO) and clinical outcomes using the Thompson-Epstein scoring systems [3] in 12 patients with Pipkin I and I fractures managed surgically with a TFO approach.

\section{Patients and Methods}

We treated 12 patients with a Pipkin I and II between
2010 and 2014. 8 were men and 4 were women with the average age was $30.5(21 \sim 50)$ years at the time of injury. The causes of injury were motor-vehicle accidents in 9 and a fall from a height in 3 . After the injury to emergency department, time last $2 \mathrm{~h} \sim 3 \mathrm{~d}$, average of $4 \mathrm{~h}$. All patients underwent X-ray and CT of the pelvis with $3 \mathrm{~mm}$ cuts. Major associated injuries were found in 9 patients. Facial injury in 2, tibia fracture in 2, multiple rib fractures in 2, humerus fracture in 1 , hemorrhagic shock in 1 and sciatic nerve injury in 1 patients. According to the Pipkin classification, 8 fractures were classified as type I and 4 as type II.

\begin{tabular}{|c|c|c|}
\hline Scale & Clinical & Radiographic \\
\hline $\begin{array}{l}\text { Excellent } \\
\text { (all of the following) }\end{array}$ & $\begin{array}{l}\text { No pain } \\
\text { Full range of hip motion } \\
\text { No limp }\end{array}$ & $\begin{array}{l}\text { Normal relationship between head and acetabulum } \\
\text { Normal articular cartilaginous space } \\
\text { Normal density of femoral head } \\
\text { No spur formation } \\
\text { No calcification in capsule }\end{array}$ \\
\hline Good & $\begin{array}{l}\text { No pain } \\
\text { Free motion ( } 75 \% \text { of normal hip) } \\
\text { No more than a slight limp }\end{array}$ & $\begin{array}{l}\text { Normal relationship between head and acetabulum } \\
\text { Minimal narrowing of cartilage space } \\
\text { Minimal de-ossification } \\
\text { Minimal spur formation } \\
\text { Minimal capsular calcification }\end{array}$ \\
\hline $\begin{array}{l}\text { Fair } \\
\text { (one or more of the following) }\end{array}$ & $\begin{array}{l}\text { Pain but not disabling } \\
\text { Limited motion of hip, no adduction deformity } \\
\text { Moderate limp }\end{array}$ & $\begin{array}{l}\text { Moderate narrowing of cartilage space } \\
\text { Motting of head, areas of sclerosis and decreased density } \\
\text { Moderate spur formation } \\
\text { Moderate to severe capsular calcification } \\
\text { Depression of subchondral cortex of the femoral head }\end{array}$ \\
\hline $\begin{array}{l}\text { Poor } \\
\text { (one or more of the following) }\end{array}$ & $\begin{array}{l}\text { Disabling pain } \\
\text { Marked limitation of motion or adduction deformity } \\
\text { Redislocation }\end{array}$ & $\begin{array}{l}\text { Almost complete obliteration of cartilaginous space } \\
\text { Relative increase in density of femoral head } \\
\text { Subchondral cyst formation } \\
\text { Sequestrae formation } \\
\text { Gross deformity of femoral head } \\
\text { Severe spur formation } \\
\text { Acetabular sclerosis }\end{array}$ \\
\hline
\end{tabular}

Fig. 2. Thompson and Epstein evaluation criteria [3].

After consultion related departments to stable basic condition, 12 patients were treated with closed reduction of hip dislocation in emergency department, of which 11 cases were successful, one case was failure (this patient transferred to hospital three days after injury). All underwent X-ray of the hip to confirm a good location. Patients with continued hip instability after closed reduction were treated with distal femoral traction. The average time of admission to operation is $3 \mathrm{~d}$.

\section{Surgical Technique}

We used the surgery with the patients in the lateral position on a standard flat radiolucent table using the previously described technique for TFO. The original approach of GANZ was strictly followed without modification [4]. The piriformis was tagged and released, but the short external rotators (gemelli and obturator internus) and inferior capsule were preserved during the approach. We identified the posteroinferior-most extent of the traumatic capsulotomy and protected it with a heavy suture to prevent further inferior extension of the capsulotomy at the time of surgical dislocation. The femoral head fracture was repaired first with headless variable-pitch screws (Herbert ZIMMER) countersunk below the articular surface. The repaired femoral head then was reduced. After gentle reduction of the hip, the capsule was repaired but not tightened to avoid tension on the retinacular vessels that may lead to a drop in the perfusion of the femoral head. The trochanteric osteotomy was repaired using either $3.5-\mathrm{mm}$ cortical screws or $6.5-\mathrm{mm}$ cancellous screws.

Postoperatively, pain was managed with patient-controlled analgesia for the first 48 hours. Compression stockings were applied while administration of low-molecular-weight heparin was not a routine to avoid deep venous thrombosis. Radiation therapy was administered within 48 hours of surgery to prevent HO. Indomethacin which reduce the risky of HO was not given to 12 patients. Patients after operation were treated with distal femoral traction for two weeks, and then instructed to continue non-weight-bearing for 8 weeks. During this period, range-of-motion exercises of the hip were instituted guided by pain. Hip flexion more than $90^{\circ}$, adduction and internal rotation were restricted for approximately 3 months. We followed patients clinically and radiographically at 4 and 8 
weeks postoperatively and every 3 months afterward. At each time, patients were examined by the treating surgeon. Clinical outcome scores were calculated using the Thompson and Epstein scales, which accounts for pain, function, and radiographic appearance and is graded as excellent, good, fair, or poor. HO was graded using the Brooker classification [5].

\section{Results}

12 patients were followed up for 1--4 years (an average of 26 years). Trochanteric osteotomies were visible radiographic union for an average of 10 weeks (range, 6-12 weeks). 12 patients had radiographic union of fractures without hardware failure, loss of fixation, or progressive loss of joint space at latest follow up. According to Thompson and Epstein scales, the overall clinical outcomes were excellent in 6 , good in 5, fair in 1 and poor in 0 . The patient with a fair clinical outcome has failure closed reduction hip dislocation. Heterotopic ossification was found in one patient (Brooker type I). The patient did not elected to undergo surgical excision of the ectopic bone.
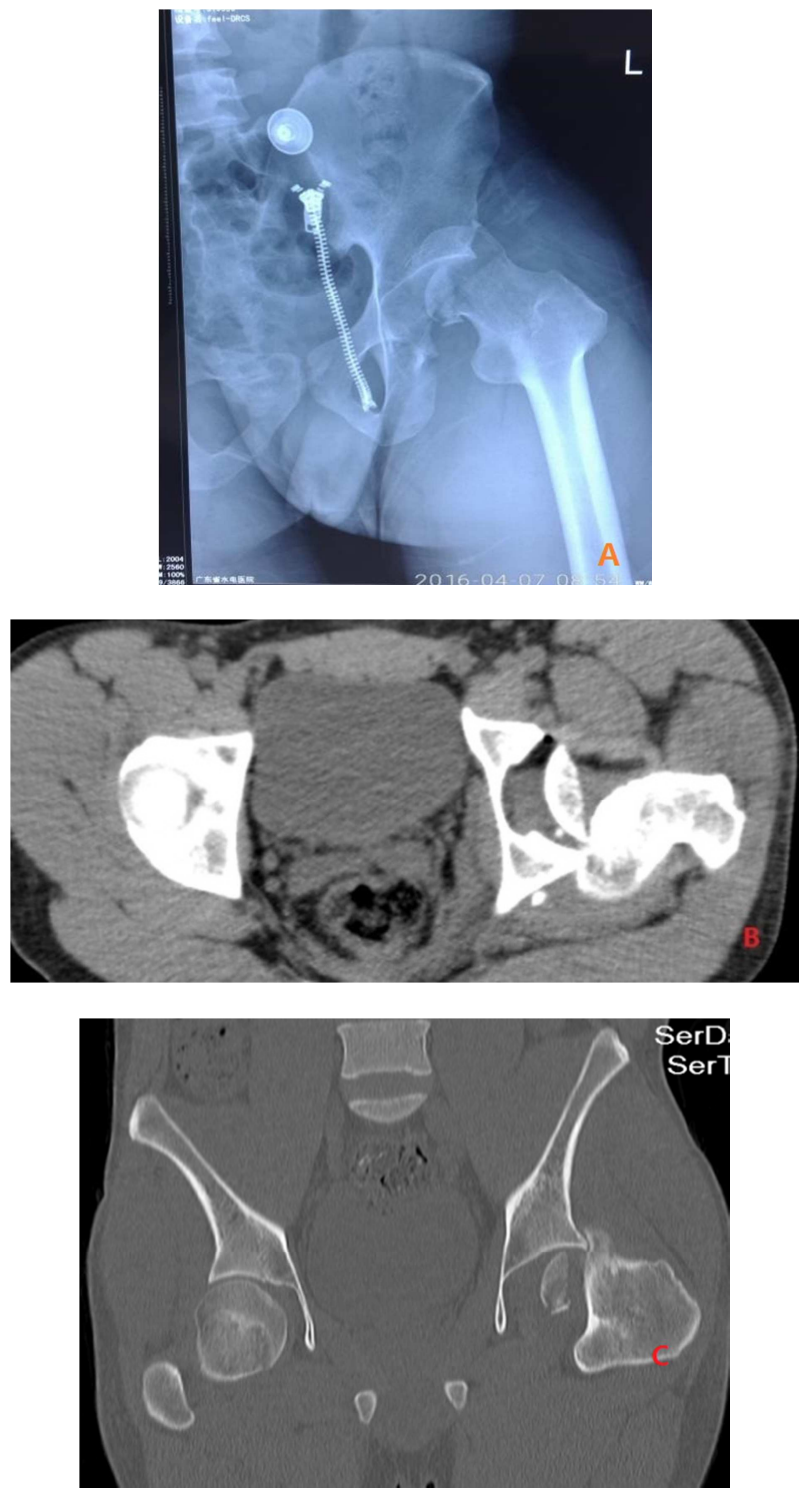

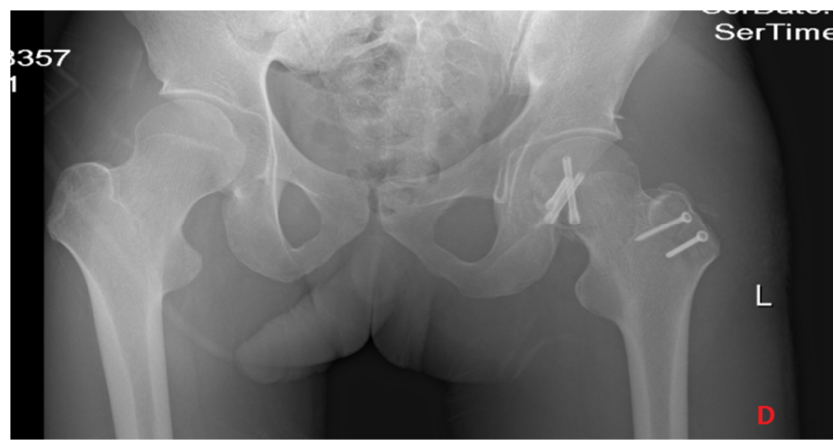

Fig. 3. A typical case: a 27-year-old man with Pipkin type I fracture dislocation left femoral head $(A)$, plain radiograph and $C T(B-C)$, he was managed by open reduction and Herbert screws fixation through TFO (D).

\section{Discussion}

Femoral head fracture associated with posterior hip dislocation is an uncommon but severe injury. It was first described by Dr. John Birkett in 1869.The femoral head fracture itself may lead to the subsequent complications such as heterotopic ossification, avascular necrosis of the femoral head and osteoarthritis may lead to a restriction in hip function and permanent disability even in young patients [6]. Although indications for surgical management are quite clear, controversies still remain regarding the treatment of Pipkin type I and type II femoral head fractures, preferred surgical approach and whether to perform fixation or excision of the fracture fragment [7]. The principles of treatment include prompt reduction of the associated hip dislocation, early anatomic reduction, rigid fixation of large fragments, restoration of hip congruency and stability and removal of small and comminuted intra-articular fragments [8].

We recommend closed reduction of hip dislocation as soon as possible, it extremely helpful for joint function recovery. The group of 12 patients underwent Allis manual reduction hip dislocation in emergency department, including seven cases within $6 \mathrm{~h}$ after injury, two cases of injury within $12 \mathrm{~h}$. All patients got the excellent or good overall clinical outcomes except one case was failure to reduction. Although the number of cases is small, we advocate Pipkin I, type II fracture patients as early as possible in the closed reduction under anesthesia. A study proved that once Pipkin fracture occurred, dominated artery were oppressed, leading to the formation of local thrombosis, leading to vascular occlusion, so that femoral head blood supply reduction or loss. They are very confirm that joint reduction must be performed immediately. [9]

The matter of which operative approach should be used for the surgical treatment of femoral head fractures remains controversial [10]. Numerous open surgical approaches to the hip joint have been described for use in femoral head fractures [11]. The anterior approaches to femoral head fractures include the Smith-Peterson approach and modified Hueter approach [12]. Advantages to anterior approaches include improved visualization of anterior-based femoral head fractures for reduction and fixation, decreased operative time, and lower rates of AVN. Disadvantages include higher rates of heterotopic ossification (HO) compared to posterior 
approaches, decreased visualization of associated posterior wall fractures, and decreased access posteriorly, especially critical in the presence of irreducible incarcerated fracture dislocations. The posterior approach to femoral head fractures involves the standard Kocher-Langenbeck approach [13]. The posterior approach is advantageous for irreducible, incarcerated femoral head fracture dislocations, in which posterior soft tissues, including the piriformis tendon and sciatic nerve, can block reduction of the femoral head. In addition, it is a favorable approach in femoral head injuries with associated acetabular fractures. A reported disadvantage of the standard posterior approach for femoral head fractures is an increased rate of AVN. The main disadvantage to the posterior approach is that femoral head access is limited and reduction and fixation of anterior femoral head fractures are often difficult [14]. The TFO, or digastric osteotomy, was originally described by Ganz and colleagues. In this technique, a posterior approach to the hip joint is modified by the addition of a digastric trochanteric osteotomy to allow for anterior dislocation of the hip joint and preservation of the posterior blood supply (medial femoral circumflex artery (MCFA) [15], the most important artery for femoral head ). Advantages of the digastric osteotomy in the treatment of femoral head fractures include complete access to the femoral head and acetabulum for reduction and fixation, with good outcomes reported for Pipkin injuries. Disadvantages to the digastric osteotomy include trochanteric nonunion, but probability of occurrence is very small [11].

Current treatment of femoral head fractures commonly used compression screw which can be divided into two categories: metal screws and absorbable screws. Two types of screws, each with advantages and disadvantages [16]. Absorbable screws [17], although have good histocompatibility and do not affect the radiologically fracture healing, but undenied its poor shear force. There is high risk of breakage, if the fracture is not completely healed before disintegrating, there must lead to serious consequences. Although the strength of conventional metal screws meet the needs healing, the "large tail" increased destruction of the femoral head. Herbert screw has been widely used for intra-articular fracture. It has the following advantages: 1.titanium alloy products, need not be removed, generally does not affect the CT or MR examination, 2. no screw nut, less damage to the femoral head, 3. good shear force and anti-rotation strength [18]. All cases of femoral head fractures were adopted Herbert screw fixation, and in the postoperative follow-up do not appear screw loose, shift, fracture or other complications indicating that the treatment is safe and effective.

\section{Conclusions}

The surgical technique of TFO allowed simultaneous exposure and fixation of femoral head fractures. The use of TFO technique gave $90 \%$ good and excellent midterm results comparable to reported outcomes of femoral head fractures. The use of Herbert screws can accelerate fracture healing and reduce complications.

\section{References}

[1] Birkett J. Description of a Dislocation of the Head of the Femur, complicated with its Fracture; with Remarks. Med Chir Trans. 1869. 52: 133-8.

[2] PIPKIN G. Treatment of grade IV fracture-dislocation of the hip. J Bone Joint Surg Am. 1957. 39-A (5): 1027-42 passim.

[3] THOMPSON VP, EPSTEIN HC. Traumatic dislocation of the hip; a survey of two hundred and four cases covering a period of twenty-one years. J Bone Joint Surg Am. 1951. 33-A (3): 746-78; passim

[4] Ganz R, Gill TJ, Gautier E, Ganz K, Krugel N, Berlemann U. Surgical dislocation of the adult hip a technique with full access to the femoral head and acetabulum without the risk of avascular necrosis. J Bone Joint Surg Br. 2001.83 (8): 1119-24.

[5] Brooker AF, Bowerman JW, Robinson RA, Riley LH Jr. Ectopic ossification following total hip replacement. Incidence and a method of classification. J Bone Joint Surg Am. 1973. 55(8): 1629-32.

[6] Giannoudis PV, Kontakis G, Christoforakis Z, Akula M, Tosounidis T, Koutras C. Management, complications and clinical results of femoral head fractures. Injury. 2009. 40(12): 1245-51.

[7] Ross JR, Gardner MJ. Femoral head fractures. Curr Rev Musculoskelet Med. 2012. 5 (3): 199-205.

[8] Oransky M, Martinelli N, Sanzarello I, Papapietro N. Fractures of the femoral head: a long-term follow-up study. Musculoskelet Surg. 2012.96 (2): 95-9.

[9] Nishino $M$, Matsumoto $T$, Nakamura $T$, Tomita $K$. Pathological and hemodynamic study in a new model of femoral head necrosis following traumatic dislocation. Arch Orthop Trauma Surg. 1997. 116 (5): 259-62.

[10] Bartonicek J, Rammelt S. History of femoral head fracture and coronal fracture of the femoral condyles. Int Orthop. 2015. 39 (6): $1245-50$.

[11] Marecek GS, Scolaro JA, Routt ML Jr. Femoral Head Fractures. JBJS Rev. 2015. 3 (11).

[12] Bauer GJ, Sarkar MR. [Injury classification and surgical approach in hip dislocations and fractures]. Orthopade. 1997. 26 (4): 304-16.

[13] Wang CG, Li YM, Zhang HF, Li H, Li ZJ. Anterior approach versus posterior approach for Pipkin I and II femoral head fractures: A systemic review and meta-analysis. Int J Surg. 2016. 27: 176-81.

[14] Swiontkowski MF, Thorpe M, Seiler JG, Hansen ST. Operative management of displaced femoral head fractures: case-matched comparison of anterior versus posterior approaches for Pipkin I and Pipkin II fractures. J Orthop Trauma. 1992. 6 (4): 437-42.

[15] Gautier E, Ganz K, Krugel N, Gill T, Ganz R. Anatomy of the medial femoral circumflex artery and its surgical implications. J Bone Joint Surg Br. 2000. 82 (5): 679-83.

[16] Hu LY, Jia QY, Yu Y, Cao Y, Zheng SQ. [Clinical effects of internal fixation with Herbert screws for the treatment of Pipkin femoral head fractures]. Zhongguo Gu Shang. 2016. 29 (2): 162-6. 
[17] Barber FA. Complications of Biodegradable Materials: Anchors and Interference Screws. Sports Med Arthrosc. 2015. 23 (3): 149-55.
[18] Herbert TJ, Fisher WE, Leicester AW. The Herbert bone screw: a ten year perspective. J Hand Surg Br. 1992. 17 (4): 415-9. 